\title{
Granulomatous Lobular Mastitis: Antituberculous Treatment and Outcome in 22 Patients
}

\author{
Lu Liua,b Fei Zhoua,c Xiaoxia Zhang ${ }^{d}$ Shuchen Liua,c Liyuan Liua,c Yujuan Xianga,c \\ Mingming $\mathrm{Guo}^{a}{ }^{a} \mathrm{c}$ Lixiang $\mathrm{Yu}^{\mathrm{a}} \mathrm{c}$ Fei Wang ${ }^{\mathrm{a}} \mathrm{c}$ Zhongbing Ma ${ }^{\mathrm{a}, \mathrm{c}}$ Liang $\mathrm{Li}^{\mathrm{a}, \mathrm{c}}$ \\ Dezong $\mathrm{Gao}^{\mathrm{a}, \mathrm{c}}$ Qiang Zhang ${ }^{\mathrm{a}, \mathrm{c}}$ Qinye $\mathrm{Fu}^{\mathrm{a}, \mathrm{c}}$ Zhigang $\mathrm{Yu}^{\mathrm{a}, \mathrm{c}}$ \\ a Department of Breast Surgery, The Second Hospital of Shandong University, Jinan, Shandong, China; \\ ${ }^{b}$ Department of Breast Surgery, Qingdao Municipal Hospital Group, Qingdao, Shandong, China; \\ 'Institute of Translational Medicine of Breast Disease Prevention and Treatment, Shandong University, Jinan, Shandong, China; \\ dDepartment of Thyroid and Breast Surgery, Linyi People's Hospital, Linyi, Shandong, China
}

\section{Keywords}

Granulomatous lobular mastitis - Clinical presentation . Management - Antituberculous therapy

\section{Summary}

Background: Granulomatous lobular mastitis (GLM) is a rare chronic inflammatory condition of the breast. The purpose of this study was to describe antituberculous treatment of GLM and the long-term follow-up outcome. Methods: This retrospective study included 22 patients who had been histopathologically diagnosed with GLM at the Second Hospital of Shandong University from January 2011 to March 2015. Clinical characteristics, ultrasonography and mammography findings, laboratory tests, treatment regimens, follow-up information, and recurrences were recorded. Results: All patients were female with a median age of 29 (range 23-44) years. The most common symptom was a breast mass with or without pain. Large irregular hypoechoic masses could be found in the breast ultrasounds of 13 patients. All patients received triple antituberculous therapy. During a median follow-up period of 40 months, 3 patients were lost to follow-up; of the remaining 19 patients, 18 achieved clinical complete remission and no recurrences were observed. Conclusion: GLM is an unusual benign breast condition that mimics breast carcinoma in its clinical and imaging presentation. Antituberculous therapy seems to be an effective alternative option in the treatment of GLM.

Lu Liu and Fei Zhou contributed equally to this work.

\section{Introduction}

Granulomatous lobular mastitis (GLM), as a rare chronic benign inflammatory disorder of the breast, was first defined by Kessler and Wolloch in 1972 [1]. It usually affects women of child-bearing age, with the average age being 35 years [2]. Patients with GLM have a great diversity of symptoms but most commonly present with a breast mass with or without pain and sometimes skin ulcerations and sinus or fistula formation [3]. The etiology of GLM is still unknown. Several factors have been reported to be related, including microbiologic agents, hormonal effects, and immunologic disorder [4].

There is currently no consensus as to the ideal first-line treatment regimen. The main treatment approaches include antibiotics with repeated drainage, wide surgical excision or mastectomy, oral steroids, immunosuppression with methotrexate, and close followup [5]. The recurrence rate remains high even after mastectomy; therefore, nonsurgical management including steroids, methotrexate, azathioprine, and close observation only are becoming more popular [6]; however, potential side effects limit the usage of drug therapy. Moreover, before complete remission, many patients undergo multiple surgical procedures and repeated antimicrobial treatment over months or years, suggesting limited effectiveness of these approaches in GLM.

In this article, we described the clinical presentation, use of antituberculous treatment, and outcomes of 22 patients with GLM.

\section{Methods}

Patients

This is a retrospective single-arm clinical assessment study of patients referred to the Second Hospital of Shandong University, China, with a diagnosis of GLM having received antituberculous treatment from January 2011 to Janu-

\section{KARGER}

(๑) 2018 S. Karger GmbH, Freiburg 
ary 2015. Patients with any history of malignancy were excluded. Vacuum-assisted biopsy or incisional biopsy was performed depending on the clinical findings at the time of admission. Mammary tuberculosis was excluded by tuberculin skin test, chest radiography, acid-fast staining, and careful histopathologic examination.

\section{Histopathologic Examination}

The diagnosis of GLM is based on pathologic findings and must rule out other possible diseases. In this study, histopathologic results were confirmed by 2 pathologists. The specific appearance of GLM is characterized by non-caseating granulomas involving the mammary lobules (fig. 1). Other possible granulomatous inflammatory breast diseases, including Wegener's granulomatosis, granulomatous reaction secondary to sarcoidosis, and foreign body reaction, were excluded.

\section{Clinical and Imaging Findings}

The demographic, clinical, and histopathologic data of patients were collected. The imaging findings were assessed in accordance with the Breast Imaging Reporting and Data System (BI-RADS) criteria. Etiologic factors were recorded at the time of presentation, including smoking, alcohol abuse, and body mass index.

\section{Treatment}

Lumpectomy or extended lumpectomy were performed in patients who presented with only a breast mass but no erythematous skin changes or fistulae. Patients with breast skin changes or abscess/fistula formation received antibiotics for an average of 7 days (range 5-10 days). After discharge from hospital, triple anti-tuberculosis therapy (rifampicin $0.45 \mathrm{~g} /$ day, isoniazid $0.3 \mathrm{~g} / \mathrm{day}$, and ethambutol $0.75 \mathrm{~g} /$ day) was given to patients for a duration of 6-12 months (fig. 2); liver and kidney function were monitored on a monthly basis.

\section{Follow-Up}

Patients were followed monthly for symptoms (e.g., pain and macroscopic appearance of the breast) and side effects of the antituberculous treatment (e.g., nausea, vomiting, and impaired liver function). Changes in mass size and abscess/fistula formation were recorded in detail. Side effects were also recorded during reexaminations. After treatment completion, patients were reviewed every 3 months.

Complete remission was defined as the absence of a breast mass or signs of breast inflammation after finishing medical treatment and no recurrence after 6 months of follow-up. Patients in whom the breast mass did not resolve completely were considered as having partial remission. If there was no change in the breast mass or inflammatory signs at the last clinical visit, the patient was defined as a non-responder [5].

\section{Results}

\section{Patient Characteristics}

A total of 26 GLM patients were diagnosed and treated in this study. 4 patients received surgical treatment $(n=3)$ or steroid treatment $(\mathrm{n}=1)$ and were excluded from analysis. The remaining 22 patients received triple anti-tuberculosis therapy; patient characteristics are summarized in table 1. Tuberculin skin test and chest radiography were negative in all patients, and acid-fast staining was also negative in pathologic sections.

All patients included were ethnic Han women with a median age of 29 years (range 23-44 years). 1 patient was diagnosed with rheumatoid arthritis in the past 4 months, and 1 patient had a history of abdominal tuberculosis (table 2). All patients were married and had 1 or more children (table 2); none had a history of oral contraceptive use.
Fig. 1. Histopathologic findings for granulomatous lobular mastitis. A non-caseating granuloma consisting of lymphocytes, multinucleated giant cells, epithelioid histiocytes, and a small amount of neutrophils, limited to a lobule of the breast (hematoxylin \& eosin, $\times 40$ ).

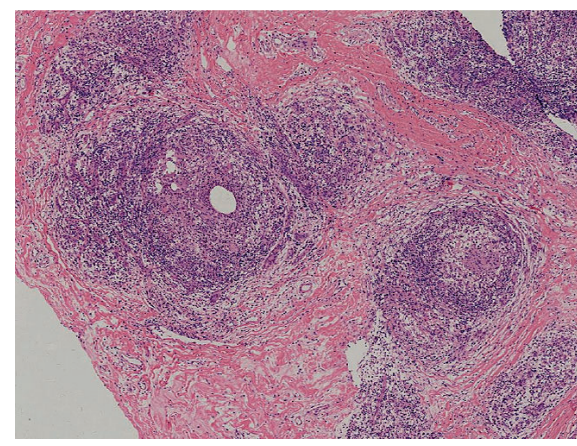

Fig. 2. Management and treatment of granulomatous lobular mastitis.
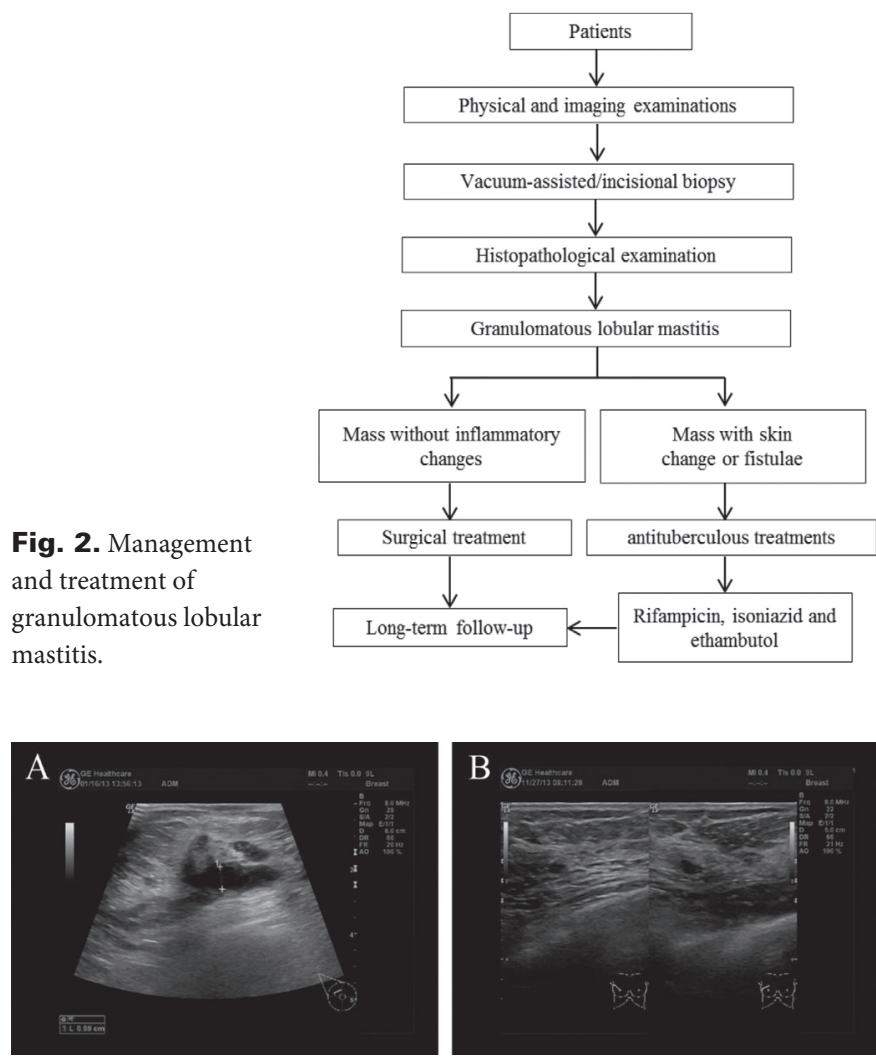

Fig. 3. Breast ultrasound presentation of granulomatous lobular mastitis. A Irregular hypoechoic mass before treatment; B 10 months after treatment with antituberculous therapy.

\section{Clinical and Imaging Presentation}

Most patients had unilateral disease (bilateral $n=1$ ). Lesions were located in the subareolar region of the breast in 13 patients. The mean size of the mass was $6.03 \pm 2.99 \mathrm{~cm}$ (range 1.2-12 cm). 2 patients developed erythema of the lower extremities over the course of disease (table 3). Ultrasonography was done in all patients (fig. 3).

\section{Treatment and Outcome}

Prior to presenting to hospital, 10 patients did not receive any treatment for GLM. 12 patients received antimicrobial agents orally or by intravenous infusion, including $\beta$-lactams (66.7\%), macrolides $(16.7 \%)$, nitroimidazoles $(8.3 \%)$, and quinolones $(8.3 \%)$. However, clinical symptoms did not improve with treatment. 
Table 1. Demographics, clinical presentation, imaging, treatment, and outcome of 22 patients with granulomatous lobular mastitis

\begin{tabular}{|c|c|c|c|c|c|c|c|c|c|}
\hline $\begin{array}{l}\text { Patient } \\
\text { no. }\end{array}$ & $\begin{array}{l}\text { Age at } \\
\text { diagnosis, } \\
\text { years }\end{array}$ & $\begin{array}{l}\text { Unilateral/ } \\
\text { bilateral }\end{array}$ & $\begin{array}{l}\text { Size of } \\
\text { mass, } \\
\mathrm{cm}\end{array}$ & $\begin{array}{l}\text { Subareolar } \\
\text { region } \\
\text { lesions }\end{array}$ & $\begin{array}{l}\text { Duration of } \\
\text { symptoms before } \\
\text { diagnosis, months }\end{array}$ & Ultrasound & $\begin{array}{l}\text { Treatment } \\
\text { prior to } \\
\text { presenting } \\
\text { to hospital }\end{array}$ & $\begin{array}{l}\text { Follow-up, } \\
\text { months }\end{array}$ & Outcome \\
\hline 1 & 27 & bilateral & 11 & yes & 3 & fluid sonolucent area & antibiotics & 53 & $\mathrm{CR}$ \\
\hline 2 & 30 & right & 4 & yes & 12 & hypoechoic mass & none & 48 & $\mathrm{CR}$ \\
\hline 3 & 34 & right & 4 & yes & 3 & ductal dilatation & antibiotics & 47 & $\mathrm{CR}$ \\
\hline 4 & 29 & left & 4 & no & 2 & mixed-echoic mass & none & lost & - \\
\hline 5 & 30 & right & 6 & no & 0.3 & hypoechoic mass & antibiotics & 44 & $\mathrm{CR}$ \\
\hline 6 & 28 & left & 3.5 & yes & 8 & mixed-echoic mass & antibiotics & 43 & $\mathrm{CR}$ \\
\hline 7 & 29 & left & 7 & no & 1 & hypoechoic mass & antibiotics & 43 & CR \\
\hline 8 & 33 & right & 1.2 & yes & 1 & hypoechoic mass & antibiotics & 43 & $\mathrm{CR}$ \\
\hline 9 & 27 & left & 10 & no & 2 & hypoechoic mass & none & 43 & $\mathrm{CR}$ \\
\hline 10 & 36 & right & 6 & no & 0.5 & hypoechoic mass & none & 42 & $\mathrm{CR}$ \\
\hline 11 & 27 & right & 10 & yes & 5 & ductal dilatation & none & 40 & $\mathrm{PR}$ \\
\hline 12 & 28 & left & 5 & yes & 0.5 & hypoechoic mass & none & 31 & CR \\
\hline 13 & 42 & left & 8 & yes & 12 & isoechoic mass & none & 30 & $\mathrm{CR}$ \\
\hline 14 & 36 & left & 4 & yes & 0.5 & mixed-echoic mass & none & 28 & $\mathrm{CR}$ \\
\hline 15 & 44 & left & 3 & no & 0.5 & hypoechoic mass & antibiotics & 27 & $\mathrm{CR}$ \\
\hline 16 & 36 & left & 4 & no & 0.3 & hypoechoic mass & none & 26 & $\mathrm{CR}$ \\
\hline 17 & 27 & right & 12 & yes & 2 & fluid sonolucent area & antibiotics & 24 & $\mathrm{CR}$ \\
\hline 18 & 23 & right & 3 & yes & 2 & hypoechoic mass & none & lost & - \\
\hline 19 & 32 & right & 7 & yes & 3 & normal & antibiotics & lost & - \\
\hline 20 & 33 & right & 10 & no & 2 & hypoechoic mass & antibiotics & 23 & $\mathrm{CR}$ \\
\hline 21 & 28 & left & 6 & no & 2 & hypoechoic mass & antibiotics & 23 & CR \\
\hline 22 & 27 & left & 4 & yes & 5 & hypoechoic mass & antibiotics & 23 & $\mathrm{CR}$ \\
\hline
\end{tabular}

$\mathrm{CR}=$ Complete remission; $\mathrm{PR}=$ partial remission.

After admission, abscess incision and drainage was performed in 1 patient, and small tissue samples were taken during this process for histopathologic examination. Vacuum-assisted biopsy was performed in the remaining 21 patients using the Mammotome ${ }^{\mathrm{TM}}$ Biopsy System (Devicor Medical Products, Inc., Cincinnati, OH, USA). For patients with breast skin changes or abscess/fistula formation, a combination of antimicrobial agents ( $\beta$-lactam plus nitroimidazoles or quinolones plus nitroimidazoles) were used for an average of 7 days (range 5-10 days) to control the acute infection. After pathologic confirmation of GLM, patients received triple anti-tuberculosis treatment according to protocol (fig. 4). There were no severe side effects; however, mild side effects were recorded, including nausea, vomiting, and paresthesia of the fingers or feet.

A total of 3 patients were lost to follow up. For the remaining 19 patients, the median follow-up period was 40 months (range 23-53 months), and the median follow-up period after finishing anti-tuberculosis treatment was 29 months (range 11-42 months). Clinical symptoms improved after 3 months of triple anti-tuberculosis treatment, including mass shrinkage, pain relief, and sinus healing. After treatment completion, all patients underwent physical and ultrasonographic examination to determine outcome. 18 of the 19 patients achieved complete remission; 1 patient did not reach complete remission and retained a mass in her breast. No recurrences or new GLM lesions were observed in the long-term follow-up in all patients.

\section{Discussion}

Since GLM was first described as a separate type of breast disease in 1972 [1], many studies, especially in the last decade, have focused on clinical presentation and treatment options [7, 8]. However, so far, the etiology and optimal treatment of GLM are still unclear. In our study, almost all patients were of child-bearing age, and the most common complaint was a breast lump with or without pain. Antituberculous therapy proved to be an effective alternative therapy for GLM in our study.

GLM usually affects women with a history of breastfeeding or recent birth, and our study was consistent in this regard with earlier research. Gestation, breastfeeding, and hyperprolactinemia have been put forward as possible factors underlying the pathogenesis of GLM. Hormonal alterations during these processes, milk secretion, and inflammation have an effect on disease pathophysiology $[9,10]$. Other factors related to GLM include oral contraceptives, alcohol abuse, smoking, and ethnic differences [11, 12]; however, in our study, this relationship was not found as none of the patients presented with long-term use of oral contraceptives, alcohol abuse, or active smoking.

GLM was generally associated with clinical symptom of breast lump, abscess, inflammation, and mammary duct fistula or sinus in this study, and this is consistent with the literature [13]; the most common clinical presentation was breast lump with or without skin change and pain, and the most common ultrasonographic 
Table 2. Characteristics of patients with granulomatous lobular mastitis

\begin{tabular}{|c|c|}
\hline & $\mathrm{n}(\%)$ \\
\hline \multicolumn{2}{|l|}{ Age, years } \\
\hline$<25$ & $1(4.55)$ \\
\hline $25-30$ & $10(45.45)$ \\
\hline $30-35$ & $6(27.27)$ \\
\hline $35-40$ & $3(13.64)$ \\
\hline$\geq 40$ & $2(9.09)$ \\
\hline \multicolumn{2}{|l|}{ Body mass index, $\mathrm{kg} / \mathrm{m}^{2}$} \\
\hline$<24$ & $13(59.1)$ \\
\hline $24-28$ & $3(13.64)$ \\
\hline$\geq 28$ & $6(27.27)$ \\
\hline Breast disease history & $2(9.09)$ \\
\hline Rheumatoid arthritis & $1(4.55)$ \\
\hline Smoking & $0(0)$ \\
\hline Passive smoking & $11(50)$ \\
\hline Alcohol abuse & $0(0)$ \\
\hline \multicolumn{2}{|l|}{ Age at birth of first child, years } \\
\hline$<25$ & $5(22.73)$ \\
\hline $25-30$ & $14(63.64)$ \\
\hline$\geq 30$ & $3(13.64)$ \\
\hline \multicolumn{2}{|l|}{ Parity, n } \\
\hline 1 & $17(77.27)$ \\
\hline 2 & $5(22.73)$ \\
\hline \multicolumn{2}{|l|}{ Abortion, $\mathrm{n}$} \\
\hline 0 & $13(59.09)$ \\
\hline 1 & $4(18.18)$ \\
\hline$\geq 2$ & $3(13.64)$ \\
\hline \multicolumn{2}{|l|}{ Previous delivery, years } \\
\hline$<3$ & $8(36.36)$ \\
\hline $3-5$ & $7(31.82)$ \\
\hline$\geq 5$ & $7(31.82)$ \\
\hline \multicolumn{2}{|l|}{ Duration of breastfeeding, months } \\
\hline$<12$ & $3(13.64)$ \\
\hline $12-24$ & $11(50)$ \\
\hline$\geq 24$ & $5(22.73)$ \\
\hline Pregnancy but no lactation & $3(13.64)$ \\
\hline No lactation from the affected side & $6(27.27)$ \\
\hline \multicolumn{2}{|l|}{ Age at menarche, years } \\
\hline$<14$ & $11(50)$ \\
\hline$\geq 14$ & $11(50)$ \\
\hline Menopause & $1(4.55)$ \\
\hline
\end{tabular}

finding was a large irregular hypoechoic mass. In the absence of specific radiologic findings, the diagnosis of GLM is based on histopathologic findings.

There is no standard GLM treatment so far. Observational management, surgical intervention, and medical treatment are common modes of therapy [14]. Surgical intervention should be used with caution as a $16-50 \%$ recurrence rate was reported after surgical treatment [11]. To date, administration of corticosteroids for large lesions prior to surgery is recommended to help minimize lesion size and obtain better cosmetic outcome [15].

As for pharmacotherapy, corticosteroids have been used as primary treatment after surgery to prevent GLM recurrences [9]. Others have recommended that corticosteroid treatment should be used only in complicated cases because of its side effects [16]. Yabanoglu et al. [17] indicated that wide surgical excision might be
Table 3. Clinical

characteristics and presentation of patients with granulomatous

\section{lobular mastitis}

$$
\text { A }
$$

Affected side
Left

\begin{tabular}{lc}
\hline Mean size of mass, cm & $6.03 \pm 2.99$ \\
\cline { 2 - 2 } & $\mathrm{n}(\%)$ \\
\cline { 2 - 2 } Affected side & $11(50)$ \\
Left & $10(45.45)$ \\
Right & $1(4.55)$ \\
Bilateral & \\
Quadrant(s) & $4(18.18)$ \\
Upper-outer & $1(4.55)$ \\
Lower-outer & $5(22.73)$ \\
Upper-inner & $1(4.55)$ \\
Lower-inner & $11(50)$ \\
2 or more quadrants & $13(59.09)$ \\
Subareolar region lesions & \\
Clinical presentation & $12(54.55)$ \\
Mass without pain & $10(45.45)$ \\
Mass with pain & $16(72.73)$ \\
Erythematous skin & $1(4.55)$ \\
Nipple discharge & $8(36.36)$ \\
Sinus formation & $10(45.45)$ \\
Axillary lymphadenopathy & $6(27.27)$ \\
Nipple retraction & $2(9.09)$ \\
Erythema in lower extremities & \\
\hline
\end{tabular}

the preferred approach, while the recurrence rate with steroids was much higher. Recently, topical corticosteroids were also reported to be effective in the management of GLM [18]. However, most of these conclusions are based on small case series and have not been confirmed epidemiologically. Moreover, because of the potential side effects of corticosteroids, their application is limited. Immunosuppressive agents like methotrexate and azathioprine are also thought to have some value in the treatment of GLM [19], based on the perception of GLM as an autoimmune disease.

In a recent review article, Lei et al. [20] evaluated the complete remission/resolution and recurrence rates of different treatment options. 6, 9, and 5 studies with 138, 358, and 106 patients were analyzed for surgical management, oral steroids, and oral steroids plus surgical managements, respectively. The pooled estimates for complete remission rate were $90.6,71.8$, and $94.5 \%$; the pooled estimates for recurrence rate were $6.8,20.9$, and $4.0 \%$, respectively. In our study, the complete remission rate with antituberculous therapy was $94.7 \%$ (18/19), while no recurrence was observed. However, given the limited case numbers and follow-up time, further investigations are needed to better understand the role of antituberculous therapy in the managements of GLM.

Observational management may also be an acceptable approach, because more than half of the patients with GLM who did not receive any treatment were found to achieve complete remission [21]; however, it should be noted that patients were symptomatic for longer before reaching remission. Bouton et al. [3] considered GLM as a self-limiting benign condition, and they found the average time to resolution to be 7.4 months, albeit with a recurrence rate of $11 \%$.

In this study, antituberculous therapy was found to be an effective alternative treatment for patients diagnosed with GLM. Others have also reported antituberculous therapy in the treatment of 
Fig. 4. Clinical presentation of a patient with granulomatous lobular mastitis and treatment with antituberculous therapy. A Clinical presentation; B 1 month after antituberculous therapy;

C 2 months after treatment; D 5 months after treatment.

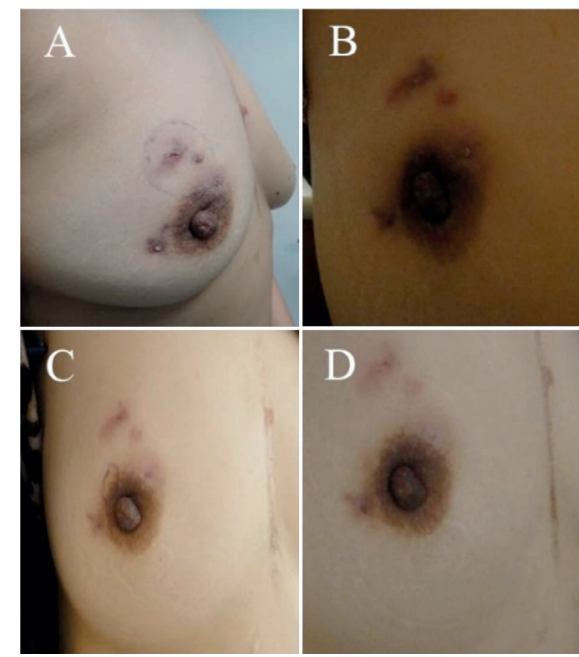

GLM: Rao et al. [22] reported that of 34 patients who completed an antituberculous treatment regimen, 33 were cured without additional surgical intervention. Velidedeoglu et al. [23] also found that antituberculous treatment was effective in the treatment of a patient with bilateral disease. Recently, Farouk et al. [24] reported that in their prospective study including 30 GLM patients, rifampicin (300 mg twice daily for 6-9 months) was an effective therapy. In contrast, Sheybani et al. [7] recently reported that 7 patients who also had a history of complete or incomplete antituberculous treatment showed symptom deterioration and no response to medication.

A relationship between GLM and Corynebacteria was first reported by Binelli et al. [25] in 1996, and reports pertaining to this link have increased over the years [26, 27]. Corynebacteria, especially C. kroppenstedtii, have been accepted as possible pathogens by some authors [28]. Interestingly, Dobinson et al. [14] conducted an antimicrobial susceptibility test for common antibiotics, and results indicated that $C$. kroppenstedtii was susceptible to rifampicin and resistant to $\beta$-lactams.

In conclusion, our results indicate that antituberculous therapy may be an effective and appropriate alternative treatment options for GLM in a number of situations. Further studies with higher patient numbers are needed to evaluate the efficacy of antituberculous therapy, and the effect must be assessed in long-term follow-up.

\section{Disclosure Statement}

This study was supported by the National Health and Family Planning Commission's Public-Benefit Project (201502027) and the Jinan City Clinical Medical Innovation Project (201602146).

\section{References}

1 Kessler E, Wolloch Y: Granulomatous mastitis: a lesion clinically simulating carcinoma. Am J Clin Pathol 1972;58:642-646.

2 Tse GM, Poon CS, Ramachandram K, Ma TK, Pang LM, Chu WC, Tang AP, Cheung H: Granulomatous mastitis: a clinicopathological review of 26 cases. $\mathrm{Pa}$ thology 2004;36:254-257.

3 Bouton ME, Jayaram L, O’Neill PJ, Hsu CH, Komenaka IK: Management of idiopathic granulomatous mastitis with observation. Am J Surg 2015;210:258262.

4 Altintoprak F, Kivilcim T, Ozkan OV: Aetiology of idiopathic granulomatous mastitis. World J Clin Cases 2014;2:852-858

5 Mahlab-Guri K, Asher I, Allweis T, Diment J, Sthoeger ZM, Mavor E: Granulomatous lobular mastitis. Isr Med Assoc J 2015;17:476-480.

6 Hladik M, Schoeller T, Ensat F, Wechselberger G: Idiopathic granulomatous mastitis: successful treatment by mastectomy and immediate breast reconstruction. J Plast Reconstr Aesthet Surg 2011;64:1604-1607.

7 Sheybani F, Sarvghad M, Naderi HR, Gharib M: Treatment for and clinical characteristics of granulomatous mastitis. Obstet Gynecol 2015;125:801-807.

8 Kok KY, Telisinghe PU: Granulomatous mastitis: presentation, treatment and outcome in 43 patients. Surgeon 2010;8:197-201.

-9 Sakurai K, Fujisaki S, Enomoto K, Amano S, Sugitani M: Evaluation of follow-up strategies for corticosteroid therapy of idiopathic granulomatous mastitis. Surg Today 2011;41:333-337.

10 Bouton ME, Winton LM, Gandhi SG, Jayaram L, Patel PN, O’Neill PJ, Komenaka IK: Temporal resolution of idiopathic granulomatous mastitis with resumption of bromocriptine therapy for prolactinoma. Int J Surg Case Rep 2015;10:8-11.
11 Ocal K, Dag A, Turkmenoglu O, Kara T, Seyit H, Konca K: Granulomatous mastitis: clinical, pathological features, and management. Breast J 2010;16:176-182.

12 Baslaim MM, Khayat HA, Al-Amoudi SA: Idiopathic granulomatous mastitis: a heterogeneous disease with variable clinical presentation. World J Surg 2007;31: 1677-1681.

13 Handa P, Leibman AJ, Sun D, Abadi M, Goldberg A: Granulomatous mastitis: changing clinical and imaging features with image-guided biopsy correlation. Eur Radiol 2014;24:2404-2411.

14 Dobinson HC, Anderson TP, Chambers ST, Dooque MP, Seaward L, Werno AM: Antimicrobial treatment options for granulomatous mastitis caused by Corynebacterium species. J Clin Microbiol 2015;53: 2895-2899.

15 Atak T, Sagiroglu J, Eren T, Ali OI, Alimoglu O: Strategies to treat idiopathic granulomatous mastitis: retrospective analysis of 40 patients. Breast Dis 2015;35:19-24. 16 Mizrakli T, Velidedeoglu M, Yemisen M, Mete B, Kilic F, Yilmaz H, Ozturk T, Ozaras R, Aydogan F, Perek A: Corticosteroid treatment in the management of idiopathic granulomatous mastitis to avoid unnecessary surgery. Surg Today 2015;45:457-465.

17 Yabanoğlu H, Çolakoğlu T, Belli S, Aytac HO, Bolat FA, Pourbagher A, Tezcaner T, Yildirim S, Haberal M: A comparative study of conservative versus surgical treatment protocols for 77 patients with idiopathic granulomatous mastitis. Breast J 2015;21:363-369.

18 Altintoprak F: Topical steroids to treat granulomatous mastitis: a case report. Korean J Intern Med 2011;26: 356-359.

19 Gurleyik G, Aktekin A, Aker F, Karagulle H, Saglamc A: Medical and surgical treatment of idiopathic granulomatous lobular mastitis: a benign inflammatory disease mimicking invasive carcinoma. J Breast Cancer 2012;15:119-123.
20 Lei X, Chen K, Zhu L, Song E, Su F, Li S: Treatments for idiopathic granulomatous mastitis: systematic review and meta-analysis. Breastfeed Med 2017;80:1099.

21 Lai EC, Chan WC, Ma TK, Tang AP, Poon CS, Leong HT: The role of conservative treatment in idiopathic granulomatous mastitis. Breast J 2005;11:454-456.

22 Rao NY, Su FX, Zeng YJ, Jia WJ, Li SR, Wu JN, Liu JQ, Song EW: Anti-tuberculosis treatment for idiopathic granulomatous mastitis mimicking breast cancer: a retrospective review of 36 cases. J Cancer Res Ther Oncol 2014;2:1-6.

23 Velidedeoglu M, Kilic F, Mete B, Yemisen M, Celik V, Gazioglu E, Ferahman M, Ozaras R, Yilmaz $\mathrm{MH}$ Aydogan F: Bilateral idiopathic granulomatous mastitis. Asian J Surg 2016;39:12-20.

24 Farouk O, Abdelkhalek M, Abdallah A, Shata A, Senbel A, Attia E, Elghaffar MA, Mesbah M, Soliman N, Amin M, El-Tantawy D: Rifampicin for idiopathic granulomatous lobular mastitis: a promising alternative for treatment. World J Surg 2017;41:1313-1321.

25 Binelli C, Lorimier G, Bertrand G, Parvery F, Bertrand AF, Verriele V: Granulomatous mastitis and corynebacteria infection. Two case reports. J Gynecol Obstet Biol Reprod (Paris) 1996;25:27-32.

26 Mathelin C, Riegel P, Chenard MP, Tomasetto C, Brettes JP: Granulomatous mastitis and corynebacteria: clinical and pathologic correlations. Breast J 2005; 11:357.

27 Mathelin C, Riegel P, Chenard MP, Brettes JP: Association of corynebacteria with granulomatous mastitis. Eur J Obstet Gynecol Reprod Biol 2005;119:260-261.

28 Taylor GB, Paviour SD, Musaad S, Jones WO, Holland DJ: A clinicopathological review of 34 cases of inflammatory breast disease showing an association between corynebacteria infection and granulomatous mastitis. Pathology 2003;35:109-119. 